\title{
An analytic approach for describing and prioritizing health inequalities at the local level in Canada: a descriptive study
}

\author{
Cory Neudorf MD MHSc, Daniel Fuller PhD, Jennifer Cushon PhD, Riley Glew MPH MSc, \\ Hollie Turner MA, Cristina Ugolini MPA
}

\section{Abstract}

Background: We present the health inequalities analytic approach used by the Saskatoon Health Region to examine health equity. Our aim was to develop a method that will enable health regions to prioritize action on health inequalities.

Methods: Data from admissions to hospital, physician billing, reportable diseases, vital statistics and childhood immunizations in the city of Saskatoon were analyzed for the years ranging from 1995 to 2011 . Data were aggregated to the dissemination area level. The Pampalon deprivation index was used as the measure of socioeconomic status. We calculated annual rates per 1000 people for each outcome. Rate ratios, rate differences, area-level concentration curves and area-level concentration coefficients quantified inequality. An Inequalities Prioritization Matrix was developed to prioritize action for the outcomes showing the greatest inequality. The outcomes measured were cancer, intentional self-harm, chronic obstructive pulmonary disease, mental illness, heart disease, diabetes, injury, stroke, chlamydia, tuberculosis, gonorrhea, hepatitis $\mathrm{C}$, high birth weight, low birth weight, teen abortion, teen pregnancy, infant mortality and all-cause mortality.

Results: According to the Inequalities Prioritization Matrix, injuries and chronic obstructive pulmonary disease were the first and second priorities, respectively, that needed to be addressed related to inequalities in admissions to hospital. For physician billing, mental disorders and diabetes were high-priority areas. Differences in teen pregnancy and all-cause mortality were the most unequal in the vital statistics data. For communicable diseases, hepatitis $\mathrm{C}$ was the highest priority.

Interpretation: Our findings show that health inequalities exist at the local level and that a method can be developed to prioritize action on these inequalities. Policies should consider health inequalities and adopt population-based and targeted actions to reduce inequalities.

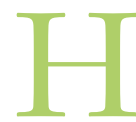
ealth equity is the principle of and commitment to incorporating social justice into health by reducing health inequalities. It implies that all people can reach their full health potential and should not be disadvantaged from attaining it because of their race, ethnicity, religion, sex, age, social class, socioeconomic status or other socially determined circumstances. ${ }^{1}$ Measuring health inequity is a difficult task and requires 2 steps. First, health inequalities, which are differences in health outcomes between different groups in the same population, must be measured. Second, health inequalities become health inequities when these differences are deemed unnecessary, avoidable, unjust and unfair. ${ }^{1}$

The health sector plays an important role in perpetuating or reducing health inequities. ${ }^{2,3}$ The Health Disparities Task Group of the Federal Provincial Territorial Advisory Committee on Population Health and Health Security suggested that the health sector can reduce or increase health inequities depending on how their programs and policies are implemented and taken up by the population. ${ }^{4}$ Focused health sector efforts to improve health care equity have the potential to reduce inequities in health outcomes. ${ }^{4-6}$ Health care equity means that health care services should be available, accessible, and acceptable to everyone in the population, and also maintain a high degree of quality. ${ }^{7}$

Limited evaluations of health inequalities also may be due to limitations in the health regions' organizational capacities or a lack of practical methods for health regions to use for planning. ${ }^{8}$ In Saskatchewan, the Ministry of Health's Strategic and Operational Directions 2013-2014 identified that collaboration with communities, other ministries and different levels of government will close the gap in health inequalities and promote health equity. ${ }^{9}$ However, the Ministry of Health did not identify specific measures or targets for evaluating health inequalities.

Competing interests: None declared.

Correspondence to: Cory Neudorf, cory.neudorf@usask.ca

CMAJ Open 2015. DOI:10.9778/cmajo.20150049 
As part of an ongoing commitment to address health inequities, Saskatoon Health Region previously compared rate ratios between the highest and lowest income neighbourhoods within the city of Saskatoon. ${ }^{10,11} \mathrm{We}$ present the Health Region's analytic approach to addressing health equity, building on the Region's past work and research conducted in Manitoba. ${ }^{12,13}$ This approach includes 3 major components: data, analysis and prioritization. Our objective was to develop an approach for measuring the extent of health inequalities at the local level.

\section{Methods}

\section{Setting}

The Saskatoon Health Region had a population of 315000 people in 2010, with $12.8 \%$ of the population aged 65 years or older. ${ }^{14}$ Our analysis was restricted to the Saskatoon Census Subdivision area, which had a population of 222189 in $2011 . .^{15}$

\section{Design}

The conceptualization of the approach we developed is based on the World Health Organization Urban HEART (Health Equity Assessment and Response Tool). ${ }^{16}$ The Urban HEART tool conceptualizes a cyclical tool with 4 areas: defining the problem (assessment), setting the agenda (response), developing policy (policy), and implementing the program (program). The analytic approach we developed is a part of the assessment area of the Urban HEART conceptualization. We adapted the approach to the Canadian context and available Canadian data, and also provided a broader range of inequality measures than those suggested by the Urban HEART tool.

\section{Outcomes}

Outcomes were defined by either the International Classification of Diseases, 9th revision, or the International Statistical Classification of Diseases or Related Health Problems, 10th revision codes or specific definitions used within the region. Appendix 1 (available at www.cmajopen.ca/content/3/4/E366/ suppl/DC1) shows the complete outcomes list, and definition and data source for each outcome.

\section{Sources of data}

In Saskatchewan, the majority of health outcome data are available in health administrative databases. The Hospital Services database includes all acute hospital visits, day surgeries and psychiatric visits for patients treated in hospitals. The health outcomes extracted from the hospital data were diabetes, heart disease, stroke, chronic obstructive pulmonary disease (COPD), cancer, injuries, mental disorders and self-harm. The Medical Service database includes physicians' fee-for-service claims. Physicians under non-fee-for-service arrangements submit shadow billings (i.e., billings that would have been submitted if the physician was working fee-for-service). The health outcomes assessed from the Medical Services database were the same as for the Hospital Services database, with the exception that self-harm was not available. Data for communicable diseases (i.e., chlamydia, gonorrhea, tuberculosis and hepatitis $\mathrm{C}$ ) were available from the
Saskatchewan Ministry of Health Integrated Public Health System. Childhood immunization data were available from the Saskatchewan Immunization Management System. Vital statistics data from the Ministry of Health were available for all-cause mortality, infant mortality, low and high birth weight, teen pregnancy and teen abortion.

For each data source, the most responsible diagnosis (i.e., the most significant medical condition that caused the person to stay in hospital) was used to calculate the numerator for each health outcome. Patients with multiple hospital visits in 1 day were counted only once. Transfers of the same patient between hospitals were removed to avoid double counting. The population on June 30th of the study year that was recorded in the Saskatchewan Population Registry, which includes all residents eligible for Saskatchewan Health benefits, was used as the denominator.

Because individual-level socioeconomic status data were not available, the unit of analysis was the dissemination area. Between 400 and 700 people resided in a dissemination area. The dissemination area was chosen as the unit of analysis because it is the smallest area of Canadian census geography, rates can be calculated within each dissemination area using reliable population denominator data and measures of deprivation were available for each dissemination area. In addition, dissemination area and deprivation data were publicly available, which facilitated replication.

Deprivation scores for each dissemination area in Saskatoon were obtained from the Institut National de Santé Publique du Quebec (INSPQ) using the Pampalon deprivation index and calculated for Saskatoon. ${ }^{17,18}$ The deprivation index includes factors for material and social deprivation derived from the 2006 Canadian Census. We used the 2006 Census because of data quality concerns for the 2011 National Household Survey. The material deprivation factor includes the proportion of people aged 15 years and older without a high school diploma, the employment:population ratio of people aged 15 years and older, and the average income of people aged 15 years and older in the dissemination area. The social deprivation factor includes the proportion of people aged 15 years and older living alone, the proportion of people aged 15 years and older who are separated, divorced or widowed, and the proportion of single-parent families. Quintiles of total deprivation were calculated by combining quintiles of material and social deprivation using the matrix developed by the Canadian Institute for Health Information (Appendix 2, available at www.cmajopen.ca/content/3/4/E366/supp1/DC1).

\section{Statistical analysis}

Inequality was examined using the disparity rate ratio, disparity rate difference and area-level concentration coefficient. The disparity rate ratio compares the relative socioeconomic variation on an outcome, by dividing the rate of the highest area by the rate of the lowest area deprivation group at a given time period. ${ }^{19-22}$ The disparity rate difference compares the absolute socioeconomic variation in a health outcome, by subtracting the rate of the lowest area deprivation group from the rate of the highest area deprivation group. ${ }^{19-22}$ 
Although the disparity rate ratio and disparity rate difference are good measures of difference between the 2 extreme socioeconomic status quintiles (i.e., Q1 v. Q5), they do not examine the differences across the quintiles (i.e., Q1-Q5). To examine distribution across the quintiles, an area-level concentration curve (ALCC) was used. ${ }^{23}$ Detailed methodological descriptions for calculating area-level concentration curves and coefficients have been published and are available in many statistical packages. ${ }^{21}$ Briefly, the cumulative proportion of the population and cumulative proportion of a health outcome were calculated by deprivation quintile. These values were plotted, and the area under this curve was used to derive the area-level concentration coefficient (Appendix 3, available at www.cmajopen.ca/content/3/4/E366/suppl/DC1). The area-level concentration coefficient can range from 0 (equality) to 1 (complete inequality). The Manitoba Centre for Health Policy suggested that values for area-level concentration coefficients represent low $(<0.06)$, medium $(0.06-0.20)$ and high $(>0.20)$ degrees of health inequality. ${ }^{12,24,25}$ Figure 1 shows 3 possible scenarios for the area-level concentration curve (coefficients $0.05,0.17$ and 0.39 ).

To examine health inequalities over time, we calculated the annual disparity rate ratio, disparity rate difference and arealevel concentration coefficient. We analyzed data up to the most recent available year for each data source: Hospital Services data (1995-2011), physician billing data (1996-2009), communicable disease data (2004-2010), childhood immunization data (2002-2011) and vital statistics data (1995-2009).

\section{Results}

Figure 2 shows the percent change in the prevalence, disparity rate ratio, disparity rate difference and area-level concentration coefficient for each health outcome in Saskatoon (complete data in Appendix 4, available at www.cmajopen.ca/content/3/4/ E366/suppl/DC1).

Hospital services (1995-2011), COPD and intentional self-harm were the most unequal conditions based on the area-level concentration coefficient, even though the arealevel concentration coefficient decreased substantially for these outcomes between 1995 and 2011.

For the physician billing data (1996-2009), all outcomes were high inequality. Diabetes (area-level concentration coefficient 0.39), stroke (area-level concentration coefficient 0.38), mental disorders (area-level concentration coefficient 0.38) and heart disease (area-level concentration coefficient 0.37 ) were the most unequal outcomes. The prevalence of diabetes in the physician billing data increased from 5.21 per 1000 population in 1995 to 11.20 in 2009 .

For the communicable diseases data (2004-2010), all outcomes were high inequality. Tuberculosis had the highest inequality. Of note, there were no cases of tuberculosis in the least deprived quintile for 1995-1999 and 2002-2003, and in 2008. The rates of childhood immunization in 2011 were 653.9 per 1000 population in Q5 (most deprived) and 838.8 per 1000 population in Q1 (least deprived), with a disparity rate ratio of $653.9 / 838.8=0.76$. The interpretation for immu- nization is somewhat counterintuitive because high immunization rates are positive.

The vital statistics data (1995-2009) showed high inequality for all-cause mortality (area-level concentration coefficient 0.23 ) and teen pregnancy (area-level concentration coefficient $0.25)$. Teen abortion was also highly unequal, although it was in the opposite direction, with the least deprived quintile having more abortions than the most deprived quintiles.

To make policy and planning recommendations for the Health Region, an Inequalities Priority Matrix was developed that combined the disparity rate ratio, disparity rate difference, area-level concentration coefficient, changes in disparity rate ratio and disparity rate difference, and prevalence for each outcome. The Inequalities Priority Matrix is not a formal statistical test but acts as a guide for identifying priorities based on changes over time and absolute inequality. The Matrix uses measures of inequality and provides a method for assigning value judgments about the equitable distribution of health outcomes by deprivation quintiles.

The Inequalities Priority Matrix is a 7-step process, and Table 1 shows the complete method for each outcome. Each step relies on determining the descending rank order of 1 of the inequality measures. Therefore, the outcomes with the highest degree of inequality have the lowest rank score. The 7 outcomes were the most recent area-level concentration coefficient, most recent disparity rate ratio, most recent disparity rate difference, percent change in disparity rate ratio between the oldest and most recent year, percent change in disparity rate difference between the oldest and most recent year, and prevalence. Scores for each ranking were then summed and sorted in ascending order. Thus, the lower the final score based on the 6 rankings, the higher the level of priority for the given outcome.

The Inequalities Priority Matrix analysis was conducted separately for each data source because of inherently important differences. For example, an admission to hospital for

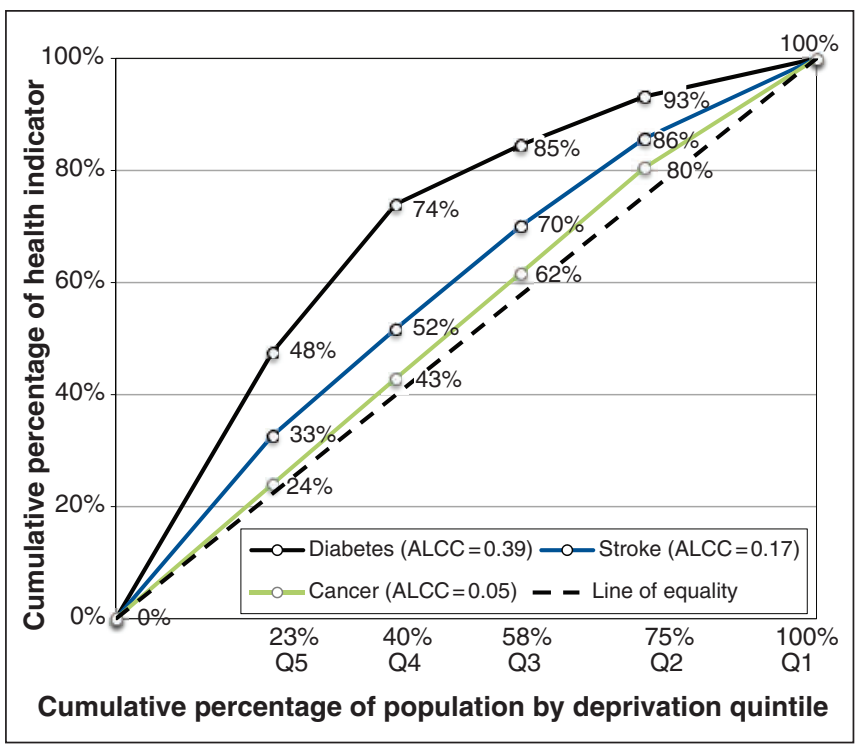

Figure 1: Diabetes, stroke and cancer area-level concentration curves and coefficients (ALCC). 
diabetes is very different from visiting a family physician for diabetes. Additionally, limitations such as shadow billing in the Medical Services database make comparisons with hospital data inappropriate. Finally, physicians, hospitals and provincial health departments have different priorities, in terms of which inequitable health outcomes to address and how to intervene.

Table 1 shows the results of the analysis using the Matrix. Injuries and COPD are the first and second priorities, respectively, to address inequalities for hospitals. The physi-

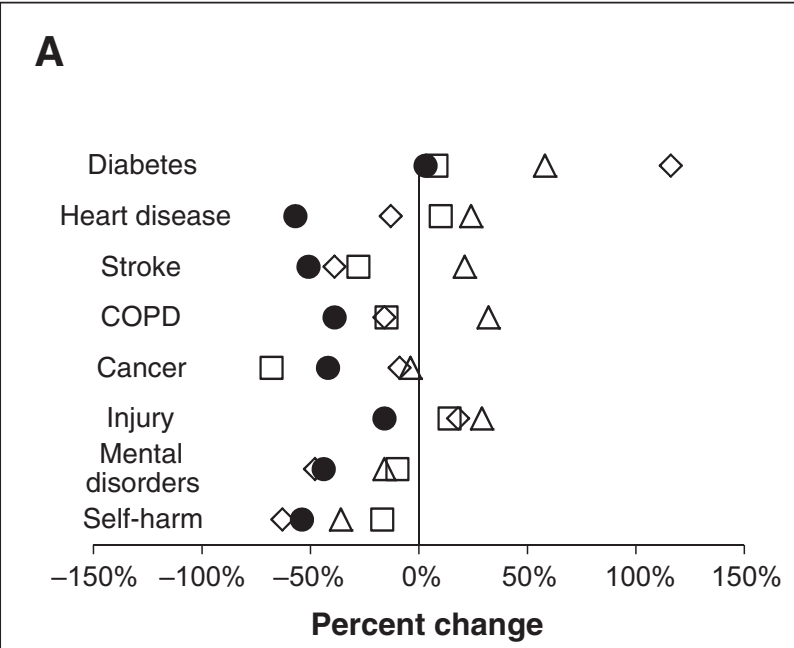

B

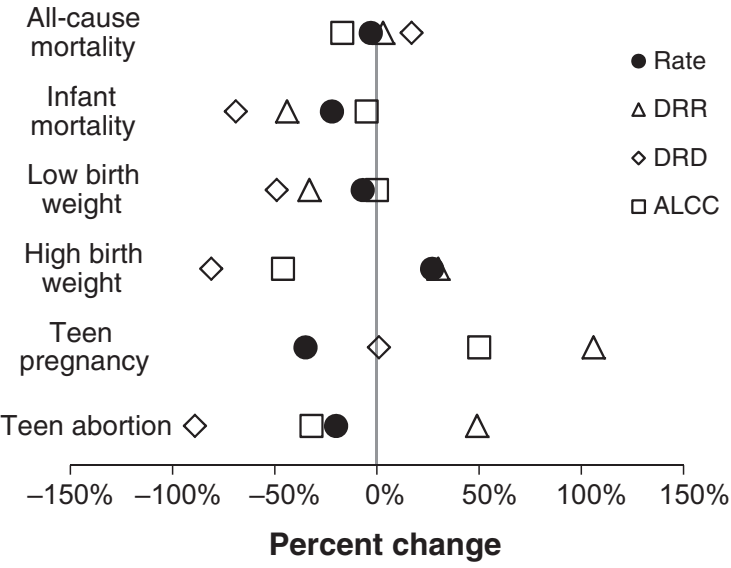

C
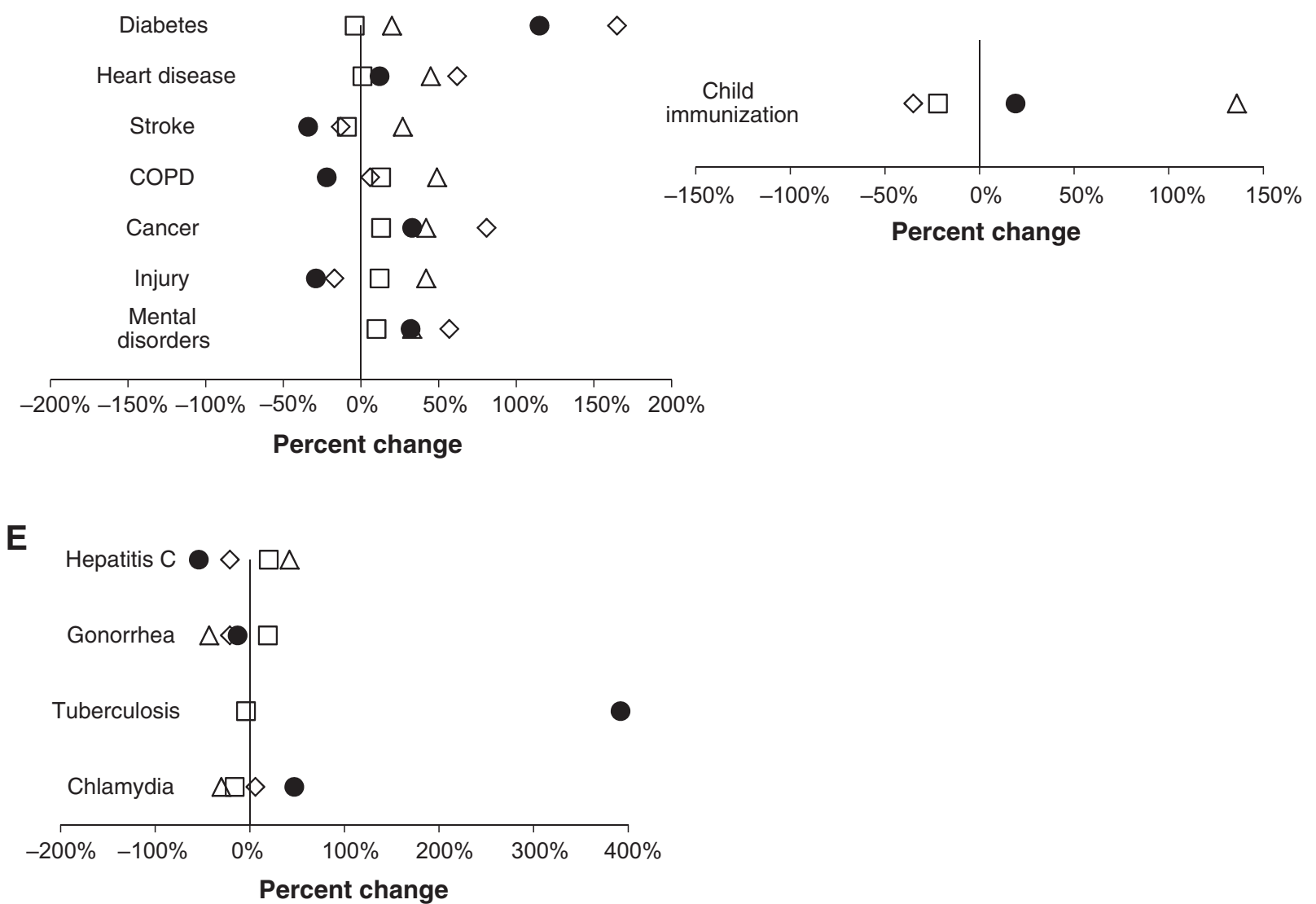

Figure 2: Percent change in rate ratio, rate difference and area-level concentration curve for each health outcome used in the Saskatoon health inequities analytic approach. (A) Admissions to hospital data, (B) physician billing data, (C) vital statistics data, (D) communicable diseases data, $(E)$ child immunization data. Note: $A L C C=$ area-level concentration coefficient, $\mathrm{DRD}=$ disparity rate difference, $\mathrm{DRR}=$ disparity rate ratio. 


\section{OPEN}

Research

cian billing data show that inequalities in mental illness and diabetes are high-priority areas. In the vital statistics data, the Matrix analysis suggested that inequalities in teen pregnancy and all-cause mortality should be addressed. For communicable diseases, hepatitis $\mathrm{C}$ is the highest priority for social inequalities. However, it should be noted that tuber- culosis is also a high priority, despite a low prevalence, because it has a high degree of inequality (area-level concentration coefficient 0.56 ). In fact, there were no cases of tuberculosis in the least deprived quintile in many of the years, making it impossible to calculate disparity rate ratio and disparity rate difference.

Table 1: Inequalities Priority Matrix (IPM) steps and final rankings for admissions to hospital, physician billing, communicable diseases and vital statistics data

\begin{tabular}{|c|c|c|c|c|c|c|c|c|c|c|c|c|c|c|}
\hline \multirow[b]{3}{*}{ Health outcome } & \multicolumn{14}{|c|}{ IPM steps* } \\
\hline & \multicolumn{2}{|c|}{ Step 1: ALCC } & \multicolumn{2}{|c|}{ Step 2: DRR } & \multicolumn{2}{|c|}{ Step 3: DRD } & \multicolumn{2}{|c|}{$\begin{array}{c}\text { Step 4: DRR \% } \\
\text { change }\end{array}$} & \multicolumn{2}{|c|}{$\begin{array}{c}\text { Step 5: DRD \% } \\
\text { change }\end{array}$} & \multicolumn{2}{|c|}{$\begin{array}{l}\text { Step 6: Rate } \\
\text { per } 1000\end{array}$} & \multicolumn{2}{|c|}{ Step 7} \\
\hline & Value & Rank & Value & Rank & Value & Rank & Value & Rank & Value & Rank & Value & Rank & $\begin{array}{l}\text { Final } \\
\text { score }\end{array}$ & $\begin{array}{c}\text { Priority } \\
\text { rank }\end{array}$ \\
\hline \multicolumn{15}{|c|}{ Hospital admissions data } \\
\hline Injury & 0.20 & 3 & 2.35 & 5 & 5.11 & 1 & 29 & 3 & 18 & 2 & 5.79 & 1 & 15 & 1 \\
\hline COPD & 0.28 & 1 & 3.42 & 2 & 2.19 & 3 & 32 & 2 & -16 & 5 & 1.71 & 5 & 18 & 2 \\
\hline Diabetes & 0.19 & 4 & 2.75 & 3 & 1.31 & 5 & 58 & 1 & 116 & 1 & 1.16 & 7 & 21 & 3 \\
\hline Mental disorders & 0.18 & 5 & 2.44 & 4 & 3.28 & 2 & -16 & 7 & -48 & 7 & 3.48 & 3 & 28 & 4 \\
\hline Heart disease & 0.16 & 6 & 1.75 & 7 & 1.43 & 4 & 24 & 4 & -13 & 4 & 2.37 & 4 & 29 & 5 \\
\hline Cancer & 0.04 & 8 & 1.18 & 8 & 0.84 & 6 & -4 & 6 & -9 & 3 & 4.66 & 2 & 33 & 6 \\
\hline Self-harm & 0.23 & 2 & 3.58 & 1 & 0.48 & 8 & -36 & 8 & -63 & 8 & 0.39 & 8 & 35 & 7 \\
\hline Stroke & 0.16 & 7 & 2.03 & 6 & 0.76 & 7 & 21 & 5 & -39 & 6 & 1.19 & 6 & 37 & 8 \\
\hline \multicolumn{15}{|c|}{ Physician billing data } \\
\hline Mental disorders & 0.38 & 3 & 9.05 & 3 & 81.4 & 1 & 33 & 5 & 57 & 4 & 42.0 & 2 & 18 & 1 \\
\hline Diabetes & 0.39 & 1 & 9.91 & 1 & 22.7 & 4 & 20 & 7 & 165 & 1 & 11.2 & 4 & 18 & 1 \\
\hline COPD & 0.37 & 5 & 9.26 & 2 & 38.1 & 3 & 49 & 1 & 6 & 5 & 20.9 & 3 & 19 & 3 \\
\hline Injury & 0.33 & 6 & 7.41 & 4 & 71.4 & 2 & 42 & 3 & -17 & 7 & 44.5 & 1 & 23 & 4 \\
\hline Heart disease & 0.37 & 4 & 7.29 & 5 & 11.2 & 5 & 45 & 2 & 62 & 3 & 5.96 & 6 & 25 & 5 \\
\hline Cancer & 0.28 & 7 & 5.56 & 7 & 11.1 & 6 & 42 & 4 & 81 & 2 & 7.54 & 5 & 31 & 6 \\
\hline Stroke & 0.38 & 2 & 6.16 & 6 & 2.26 & 7 & 27 & 6 & -13 & 6 & 1.19 & 7 & 34 & 7 \\
\hline \multicolumn{15}{|c|}{ Communicable disease data } \\
\hline Tuberculosis† & 0.56 & 1 & NA & & NA & & NA & & NA & & 0.06 & 4 & 5 & 1 \\
\hline Hepatitis C† & 0.51 & 2 & 11.14 & 1 & 1.54 & 2 & 42 & 1 & -21 & 2 & 0.37 & 3 & 11 & 1 \\
\hline Chlamydia & 0.25 & 4 & 2.96 & 3 & 5.24 & 1 & -30 & 2 & 6 & 1 & 4.85 & 1 & 12 & 2 \\
\hline Gonorrhea & 0.47 & 3 & 4.79 & 2 & 0.73 & 3 & -43 & 3 & -21 & 3 & 0.40 & 2 & 16 & 3 \\
\hline \multicolumn{15}{|l|}{ Vital statistics data } \\
\hline Teen pregnancy & 0.25 & 1 & 8.63 & 1 & 114.3 & 1 & 106 & 1 & 1 & 2 & 56.6 & 4 & 10 & 1 \\
\hline All-cause mortality & 0.23 & 2 & 2.34 & 2 & 5.38 & 3 & 3 & 4 & 17 & 1 & 5.88 & 6 & 18 & 2 \\
\hline Low birth weight & 0.06 & 6 & 1.53 & 4 & 27.8 & 2 & -33 & 5 & -49 & 3 & 61.5 & 3 & 23 & 3 \\
\hline Teen abortion & 0.21 & 3 & 0.93 & 6 & -13.2 & 6 & 49 & 2 & -89 & 6 & 195.6 & 1 & 24 & 4 \\
\hline High birth weight & 0.08 & 5 & 0.95 & 5 & -6.54 & 5 & 30 & 3 & -81 & 5 & 134.8 & 2 & 25 & 5 \\
\hline Infant mortality & 0.17 & 4 & 1.61 & 3 & 3.39 & 4 & -44 & 6 & -69 & 4 & 8.36 & 5 & 26 & 6 \\
\hline
\end{tabular}




\section{Discussion}

\section{Main findings}

The Saskatoon Health Region's health inequalities analytic approach identifies health outcomes with high inequalities between population groups of variable deprivation that warrant further investigation and should be prioritized for intervention to improve health equity at the health region level. This analytic approach addresses some of the challenges of assessing health inequalities at the local level. We believe the organizational requirements for applying the approach are reasonable and provide relevant information for policy and service delivery planning. In addition, all data are available to local health authorities across Canada, making the analysis replicable.

\section{Comparison with other studies}

We built on past research by developing the Inequalities Priority Matrix, an empirical method to prioritize further investigation and action. The Matrix considers the overall rate of the disease in a given year but prioritizes measures of inequality and changes in inequality over time. The primary strength of the Matrix is that it can be used to assign value judgments about the equitable distribution of health outcomes by deprivation quintiles. This is an approach to empirically addressing health inequalities in a local setting.

The Matrix has implications for using population or targeted prevention. ${ }^{26-28}$ Highly unequal conditions with increasing differences between the most and least deprived quintiles are prioritized. These conditions should be addressed using structural or population interventions that are feasible within the scope of the organization. It is unrealistic for most physicians to attempt to address structural inequalities of income distribution in the population on their own. However, it is feasible for physicians to provide additional care for populations with higher rates of mental disorders or diabetes.

Inequalities in all-cause mortality prioritized using vital statistics data could be addressed by broader structural changes through intersectoral partnerships. For example, Saskatchewan health regions are partners in Regional Intersectoral Committees, which bring together actors from health, education, social services and justice to develop shared priorities, evaluation plans and outcomes for action. Intersectoral action has the potential to make structural changes to social policy that may reduce social inequalities in general. ${ }^{29,30}$

Despite the focus on highly unequal conditions with a high prevalence in the population, users of the analytic approach should pay special attention to those conditions with a degree of inequality based on an area-level concentration coefficient of greater than 0.5 , regardless of prevalence. These extremely unequal outcomes may not respond well to population-level interventions and will likely require interventions based on the notion of vulnerable populations. ${ }^{31,32}$ In Saskatoon, hepatitis $\mathrm{C}$ and tuberculosis are of particular concern because they have extremely high inequality, particularly among intravenous drug users and First Nations populations.

Our approach measures health inequalities, not inequities. This implicitly assumes that the most prevalent and unequal health outcomes between socioeconomic status groups are unjust and should be acted upon. However, exceptions to this assumption should include low-prevalence, high-inequality outcomes. Local health authorities and groups using this approach must be aware of the implicit assumptions to apply value judgments about what is unjust to justify action. Additionally, the Matrix applies equal weight to all inequality measures, which could be altered based on the value users may place on the appropriateness of the different measures. We used equal weights for all inequality measures because we did not decide a priori that some inequality measures were inherently superior to others.

The strength of the analytic approach is the use of data available to local health regions in Canada. The approach balances the need for replicable and commonly used statistical techniques with the available expertise of health region staff. However, despite debate in the literature, ${ }^{33,34}$ we felt that limiting our methods to 3 complimentary but distinct measures, the disparity rate ratio, disparity rate difference and area-level concentration coefficient, would capture inequalities and be replicable.

\section{Limitations}

The analytic approach has several limitations. Addressing inequalities in health care utilization does not directly address the fundamental causes or social determinants of health that structure inequalities. However, we believe reducing inequalities in health service utilization is an important objective. Inequalities in health service utilization data do not always correspond to inequity in quality of care or prevalence of disease. Future studies should attempt to better quantify inequity by taking into account both service utilization and service need, rather than only service utilization. Data quality is an issue, particularly with respect to physician billing. In Saskatchewan, about $33 \%$ of general practitioners and $38 \%$ of specialists shadow bill (Saskatchewan Ministry of Health: personal communication, 2015). Physicians typically do not shadow bill $100 \%$ of their work, and there is no audit done in Saskatchewan on the accuracy of shadow billing. Health-seeking behaviour differs between socioeconomic status groups, which could lead to bias in the disparity calculations. In addition, billing does not represent disease, therefore, physicians may systematically report a certain disease when presented with multiple patient complaints leading to differential rates by socioeconomic status. Shadow-billing differences between socioeconomic status groups could bias the results. It is not known if socioeconomic differences in shadow billing exist. Given the long period of study, it is possible that physician turnover and changes in diagnostic practices over time could affect the results. ${ }^{35}$ In addition, the injury and self-harm data were conflated (i.e., injury data contains all self-harm attempts).

The Inequalities Priority Matrix is an attempt, although subjective, to prioritize inequalities based on available data. We did not consider change in area-level concentration coefficient. Multiple iterations of the Matrix were developed over the course of this project that included using only rate ratios and rate differences, accounting for changes in area-level concentra- 
tion coefficient over time and excluding the prevalence from the calculation. We believe the Matrix provides sufficient nuance to prioritize conditions, while being replicable. However, we also encourage other provinces or health regions to test different specifications of the Matrix and publish their findings.

The analysis is subject to the ecological fallacy because we assign deprivation from dissemination areas to each individual residing in that area. We assume all people residing in a dissemination area have the same level of deprivation, which is unlikely. ${ }^{36}$ The outcomes in this study extend from 1995 to 2011. We used deprivation data from the 2006 census. Our method assumes no change in area-level deprivation between 1995 and 2011 in Saskatoon, which has the potential for misclassification bias.

\section{Conclusion}

The Saskatoon Health Region's health inequalities analytic approach uses an empirical method and available data to describe and prioritize action to address health inequities at the local level. This approach will allow health regions to implement population-based and targeted policies to reduce health inequalities.

\section{References}

1. Whitehead M, Dahlgren G. Concepts and principles in tackling social inequities in bealth: levelling up part 1. Geneva: World Health Organization; 2006.

2. Starfield B, Shi L, Macinko J. Contribution of primary care to health systems and health. Milbank Q 2005;83:457-502.

3. Macinko J, Starfield B, Shi L. The contribution of primary care systems to health outcomes within Organisation for Economic Cooperation and Development (OECD) Countries, 1970-1998. Health Serv Res 2003;38:831-65.

4. Health Disparities Task Group of the Federal Provincial Territorial Advisory Committee on Population. Reducing health disparities — roles of the health sector: discussion paper. Ottawa: Public Health Agency of Canada; 2005:1-43.

5. Mackenbach JP. A strategy for tackling health inequalities in the Netherlands. BM7 2002;325:1029-32.

6. Mackenbach JP. Can we reduce health inequalities? An analysis of the English strategy (1997-2010). Z Epidemiol Community Health 2011;65:568-75.

7. The right to health. Geneva: World Health Organization; 2007.

8. Bell B. Actions to reduce health inequalities in Canada: a description of strategic efforts led or supported by public health organizations. Ottawa: Public Health Agency of Canada; 2009. Available: http://opha.on.ca/getmedia/1d0a2b1c-e9f6 -4a23-9344-c34c1beeff99/StrategicInitiatives-PHAC-6Mar09.pdf.aspx? ext=.pdf (accessed 2015 Sept. 17).

9. Ministry of Health: plan for 2013-2014. Saskatoon: Government of Saskatchewan; 2013:1-26.

10. Lemstra $M$, Neudorf $C$, Opondo J. Health disparity by neighbourhood income. Can 7 Public Health 2006;97:435-9.

11. Lemstra M, Neudorf C, Beaudin G. Health disparity knowledge and support for intervention in Saskatoon. Can 7 Public Health 2007;98:484-8.

12. Martens $\mathrm{P}$, Brownell $\mathrm{M}, \mathrm{Au} \mathrm{W}$, et al. Health inequities in Manitoba: Is the socioeconomic gap in health widening or narrowing over time? Winnipeg: Manitoba Centre for Health Policy; 2010:1-270.

13. Saskatoon Health Region. Better health for all. Health status reporting series 3: Advancing health equity in health care. Saskatoon: Saskatoon Health Region; 2014:1-26. Available: www.communityview.ca/pdfs/2014_shr_ phase3_advancing_healthequity_healthcare_series.pdf (accessed 2015 Sept. 4).

14. Health indicators 2012. Ottawa: Canadian Institute for Health Information; 2012. Available: https://secure.cihi.ca/free_products/health_indicators_2012_ en.pdf (accessed 2015 Oct. 1)
15. Census Subdivision of Saskatoon. Focus on geography series, 2011 Census. Available: www12.statcan.gc.ca/census-recensement/2011/as-sa/fogs-spg/Facts-csd -eng.cfm?Lang=eng\&GK=CSD\&GC=4711066 (accessed 2015 Oct. 1).

16. Urban HEART: Urban Health Equity Assessment and Response Tool: user manual. Geneva: World Health Organization; 2010.

17. Pampalon R, Hamel D, Gamache P. A comparison of individual and areabased socio-economic data for monitoring social inequalities in health. Health Rep 2009;20:85-94.

18. Pampalon R, Hamel D, Gamache P, et al. A deprivation index for health planning in Canada. Chronic Dis Can 2009;29:178-91.

19. Regidor E. Measures of health inequalities: part 1. F Epidemiol Community Health 2004;58:858-61

20. Regidor E. Measures of health inequalities: part 2. F Epidemiol Community Health 2004;58:900-3.

21. O'Donnell O, van Doorslaer E, Wagstaff A, et al. Analyzing health equity using bousebold survey data: a guide to techniques and their implementation. Washington: The World Bank; 2008:1-234.

22. Wagstaff A, Paci P, van Doorslaer E. On the measuremnt of inequalities in health. Soc Sci Med 1991;33:545-57.

23. Lorenz MO. Methods of measuring the concentration of wealth. Alexandria (VA): American Statistical Association; 1905:209-19. Available: www.jstor.org /stable/2276207 (accessed 2015 Sept. 4).

24. Roos NP, Mustard CA. Variation in health and health care use by socioeconomic status in Winnipeg, Canada: Does the system work well? Yes and no. Milbank Q 1997;75:89-111.

25. Mustard CA, Derksen S, Berthelot J-M, et al. Assessing ecologic proxies for household income: a comparison of household and neighbourhood level income measures in the study of population health status. Health Place 1999; 5:157-71.

26. Rose G. Sick individuals and sick populations. Int F Epidemiol 2001;30:427-32.

27. Frohlich KL, Mykhaloskiy E, Miller F, et al. Advancing the population health agenda. Can 7 Public Health 2004;95:392-5.

28. McLaren L, McIntyre L, Kirkpatrick S. Rose's population strategy of prevention need not increase social inequalities in health. Int 7 Epidemiol 2010; 39:372-7.

29. McCall L, Percheski C. Income inequality: new trends and research directions. Annu Rev Sociol 2010;36:329-47.

30. Fortin N, Green DA, Lemieux T, et al. Canadian inequality: recent developments and policy options. Can Public Policy 2012;38:121-45.

31. Semenza JC, Giesecke J. Intervening to reduce inequalities in infections in Europe. Am 7 Public Health 2008;98:787-92.

32. Semenza JC, Suk J, Manissero D. Intervening on high-risk or vulnerable populations? Am 7 Public Health 2008;98:1351-2.

33. Manor O, Matthews S, Power C. Comparing measures of health inequality. Soc Sci Med 1997;45:761-71.

34. Kawachi I, Kennedy BP. The relationship of income inequality to mortality: Does the choice of indicator matter? Soc Sci Med 1997;45:1121-7.

35. Song Y, Skinner J, Bynum J, et al. Regional variations in diagnostic practices. N Engl 7 Med 2010;363:45-53.

36. Oakes JM. Commentary: individual, ecological and multilevel fallacies. Int 7 Epidemiol 2009;38:361-8.

Affiliations: College of Medicine and Department of Community Health and Epidemiology (Neudorf, Glew), University of Saskatchewan, Saskatoon, Sask.; School of Public Health (Fuller), University of Saskatchewan, Saskatoon, Sask.; Public Health Observatory (Cushon, Turner, Ugolini), Saskatoon Health Region, Saskatoon, Sask.

Contributors: Cory Neudorf and Daniel Fuller conceptualized the paper. Daniel Fuller, Riley Glew, and Hollie Turner conducted the analyses. Daniel Fuller, Jennifer Cushon, and Riley Glew drafted the manuscript. All of the authors critically revised the manuscript for intellectual content, gave final approval for the version to be published and agreed to act as guarantors of the work.

Acknowledgement: The authors thank Tracey Creighton for help with the analysis of the geographic data.

Supplemental information: For reviewer comments and the original submission of this manuscript, see www.cmajopen.ca/content/3/4/E366/ suppl/DC1 